\title{
Material Flow Analysis of Fossil Fuels in China during 2000-2010
}

\author{
Sheng Wang, ${ }^{1}$ Jing Dai, ${ }^{2}$ and Meirong Su${ }^{2}$ \\ ${ }^{1}$ Chongqing Academy of Social Sciences, Chongqing 400020, China \\ ${ }^{2}$ State Key Joint Laboratory of Environmental Simulation and Pollution Control, School of Environment, \\ Beijing Normal University, Beijing 100875, China \\ Correspondence should be addressed to Jing Dai, daijing0532@mail.bnu.edu.cn
}

Received 8 November 2012; Accepted 4 December 2012

Academic Editors: N. H. Afgan, H. Aras, and K. J. Chua

Copyright () 2012 Sheng Wang et al. This is an open access article distributed under the Creative Commons Attribution License, which permits unrestricted use, distribution, and reproduction in any medium, provided the original work is properly cited.

Since the relationship between the supply and demand of fossil fuels is on edge in the long run, the contradiction between the economic growth and limited resources will hinder the sustainable development of the Chinese society. This paper aims to analyze the input of fossil fuels in China during 2000-2010 via the material flow analysis (MFA) that takes hidden flows into account. With coal, oil, and natural gas quantified by MFA, three indexes, consumption and supply ratio (C/S ratio), resource consumption intensity (RCI), and fossil fuels productivity (FFP), are proposed to reflect the interactions between population, GDP, and fossil fuels. The results indicated that in the past 11 years, China's requirement for fossil fuels has been increasing continuously because of the growing mine productivity in domestic areas, which also leads to a single energy consumption structure as well as excessive dependence on the domestic exploitation. It is advisable to control the fossil fuels consumption by energy recycling and new energy facilities' popularization in order to lead a sustainable access to nonrenewable resources and decrease the soaring carbon emissions.

\section{Introduction}

Material flow analysis (MFA), quantified by material weight instead of currency, is built on the theories of industrial metabolism and social metabolism to pursue the translation path from nature to human ecosystem as well as the final regressive sinks [1]. The basic standpoint of MFA is that environmental effects which are brought about via social economic behaviors are mainly dependent on the quantity and quality of natural resources and materials devoted in the ecosystem, and the wastes translated from the consumption sectors back to the environment.

MFA is viewed as a significant measure to study the metabolism of material and resources. Ayres and Kneese firstly presented the first material flow accounts on the national level in 1969 [2]. During 1970s-1980s, the perfection of material balance and industrial metabolism theories laid a solid foundation for MFA application in the whole ecosystem. Austria, Japan, and Germany took the lead in calculating substance and natural resources in domestic economic scope in 1990s [3]. Subsequently, developed countries such as The Netherlands, America, and Australia finished their MFA in national boundary $[1,4]$. In 2001,
EU Statistics Department published a handbook about MFA research technique applied to ecosystem for the first time in the world [5], which enormously accelerated the promotion of MFA in economic field. Muñoz and Hubacek pointed out in 2008 that the economic growth was the major source of material changes [6] Chen proposed in his study in 2007 that the driving force of the social-economic-ecological complex system was the resource, which posed unparalleled challenges on each level of the society. The quantity and quality scarcities of the diverse resources require an efficient, effective, and interdependent utilization based on overall and unified accounting [7]. In recent years, China has also done necessary studies in MFA and gained achievements in scientific research of the relationship between total material input and consumption in the national base [8-10].

In the early 1990s, The concept of "ecological rucksacks" was firstly proposed which was commonly accepted as "hidden flows" afterward [11]. This concept refers to the wastes inevitably produced in the process of resource exploitation, though it is not devoted to the social production. Without creating commercial value, it will exert a huge influence on natural and social environment. In view of this, MFA is further modified and becoming an effective tool in 
TABle 1: Population and GDP information of China during 20002010.

\begin{tabular}{lcc}
\hline Year & $\begin{array}{c}\text { Total population } \\
\text { (million) }\end{array}$ & $\begin{array}{c}\text { Gross domestic } \\
\text { product }(¥ \text { billion) }\end{array}$ \\
\hline 2000 & 1267.43 & 9921.5 \\
2001 & 1276.27 & 10965.5 \\
2002 & 1284.53 & 12033.3 \\
2003 & 1292.27 & 13582.3 \\
2004 & 1299.88 & 15987.8 \\
2005 & 1307.56 & 18308.5 \\
2006 & 1314.48 & 21087.1 \\
2007 & 1321.29 & 24953.0 \\
2008 & 1328.02 & 31404.5 \\
2009 & 1334.50 & 34090.2 \\
2010 & 1340.91 & 40120.2 \\
\hline
\end{tabular}

measuring the balance between the resource depletion and the social development [12].

In this study, MFA's method is applied to the Chinese fossil fuels as a research case with certain modifications of hidden flows, which is considered as the more exact mode in accounting resource consumption. The results can make acceptable recommendations not only in transferring materialized into dematerialized consumption pattern, but also in building a low-carbon economy and coping with global warming.

\section{Methodology and Data}

The study period, lasting from 2000 to 2010, was an important stage for China's rapid economic progress in history. The rapid growth in the fields of both economy and resource exploitation is producing far-reaching impacts in social and environmental areas for today's decision making and stratagem implement. The basic information of China during the study period is listed as background information in Table 1.

Currently, a systemic MFA framework based on the national or regional ecosystem has been initially established all over the world, which has been comprehensively applied in occidental countries. The input stream of fossil fuels was divided into two parts, direct input flows, and hidden flows. The study boundary was confined into the domestic ecosystem. The input fossil fuels which come from the domestic production and abroad import contain raw coal, oil, and natural gas, excluding secondary energy input. Moreover, Wuppertal evaluated the average ratio of global hidden flow (GHF), and the results showed that crude oil, natural gas, and raw coal were $1: 1.22,1: 1.66$ [13], and $1: 2.36$ [14], respectively in view of the fact that most coal in China belongs to bastard coal. Usually the output stream of fossil fuels refers to direct output and contaminated discharge. Due to different burning efficiencies and regional variation in technologies, it is inaccurate to calculate direct output at the end of MFA. To express the end-result of the fossil fuels in the whole process of material flow, this paper chose three indexes, consumption and supply ratio $(\mathrm{C} / \mathrm{S}$ Ratio), resource consumption intensity (RCI), and fossil fuels productivity (FFP) by considering population, GDP, and total energy input, to evaluate the influences of resource consumption in the fields of society and economy as well as environment. The three indexes are defined as follows:

$$
\begin{gathered}
\frac{\mathrm{S}}{\mathrm{C}}=\frac{\text { Consumption }}{\text { Production }- \text { Export }+ \text { Import }} \times 100 \%, \\
\mathrm{RCI}=\frac{\sum \text { Consumption } \times \mathrm{GHF}}{\text { Population }}, \\
\mathrm{FFP}=\frac{\mathrm{GDP}}{\sum \text { Consumption } \times \mathrm{GHF}},
\end{gathered}
$$

in which, the units are tsc/person ("tsc" refers to ton of standard coal (we use tsc for short in the rest part of this paper); standard coal, also known as coal equivalent, unified calorific value standard, different varieties, different energy contents of different calorific values converted to the calorific value of $7,000 \mathrm{kcal}$ per $\mathrm{kg}$ of standard coal) for RCI, $\$ /$ tsc for FFP (it is better for further comparison with other countries when we replace the currency unit from “ $¥$ ” to “\$”).

All the data sources are acquired from publications, such as Energy Statistical Yearbooks of different years [15] and China Statistical Yearbooks [16] and websites [17]. In order to seek unity of economic value and avoid inflation or deflation in different times, we defined the year of 2000 as a base year, in which year the price was chosen as constant price; therefore, pure monetary value in all the other years should be converted into a standard value of 2000. The original yield and import/outport flows of three primary fossil fuels are listed in Table 2.

According to IPCC 2006 [18], different types of fuels have their own carbon emission coefficients (we use CEC in the following part of this paper), for coal, oil, and natural gas, the transition factors are listed in Table 4. Therefore, the $\mathrm{CO}_{2}$ emission distributions will be obtained on the basis of fossil energy structure.

\section{Results and Discussion}

$\mathrm{C} / \mathrm{S}$ ratio is of a paramount importance for the national or regional sustainability. A high value $(>1)$ of $\mathrm{C} / \mathrm{S}$ ratio means more resources will be depleted, and then more wastes or disturbuances will occur along with environmental deteriorations and nonrenewable energy shortage. If the $\mathrm{C} / \mathrm{S}$ ratio is low, on the one part, it is good news that the present fossil energy supply is sufficient for demand. On the other part, it provides an important implication to readjust the energy consumption and supply relationship in the national level. The index called RCI can reflect the personal access to fossil resource in China. FFP denotes the transfer ability from raw fossil material occupation into economic value, which usually represents the efficiency of the resource consumption. The accounting of MFA and different indexes from 2000 to 2010 is shown in the following table (RMB exchange rate against the US dollar to compare this quota after conversion with different countries in a unified 
TABLE 2: The original yield and import/outport flows of three primary fossil fuels during 2000-2010.

\begin{tabular}{|c|c|c|c|c|c|c|c|c|c|}
\hline \multirow[b]{2}{*}{ Year } & \multicolumn{3}{|c|}{ Coal } & \multicolumn{3}{|c|}{ Oil } & \multicolumn{3}{|c|}{ Natural gas } \\
\hline & $\begin{array}{c}\text { Yield } \\
\text { (million tsc) }\end{array}$ & $\begin{array}{c}\text { Export } \\
\text { (million ton) }\end{array}$ & $\begin{array}{c}\text { Import } \\
\text { (million ton) }\end{array}$ & $\begin{array}{c}\text { Yield } \\
\text { (million tsc) }\end{array}$ & $\begin{array}{c}\text { Export } \\
\text { (million ton) }\end{array}$ & $\begin{array}{c}\text { Import } \\
\text { (million ton) }\end{array}$ & $\begin{array}{c}\text { Yield } \\
\text { (million tsc) }\end{array}$ & $\begin{array}{c}\text { Export } \\
\text { (billion cu.m) }\end{array}$ & $\begin{array}{c}\text { Import } \\
\text { (billion cu.m) }\end{array}$ \\
\hline 2000 & 988.55 & 55.06 & 2.17 & 232.28 & 10.30 & 70.26 & 36.46 & 3.1 & 0 \\
\hline 2001 & 1050.28 & 90.12 & 2.66 & 234.51 & 7.55 & 60.26 & 40.28 & 3.0 & 0 \\
\hline 2002 & 1107.32 & 83.89 & 11.25 & 238.03 & 7.66 & 69.40 & 43.69 & 3.2 & 0 \\
\hline 2003 & 1309.92 & 94.02 & 11.09 & 242.38 & 8.13 & 69.40 & 46.41 & 1.8 & 0 \\
\hline 2004 & 1516.15 & 86.66 & 18.61 & 2517.01 & 11.46 & 122.72 & 55.06 & 2.4 & 0 \\
\hline 2005 & 1677.85 & 71.68 & 26.17 & 259.46 & 8.07 & 126.82 & 64.86 & 2.9 & 0 \\
\hline 2006 & 1806.25 & 63.23 & 38.25 & 262.34 & 6.34 & 145.18 & 78.93 & 2.9 & 1.0 \\
\hline 2007 & 1921.35 & 53.17 & 51.01 & 267.06 & 3.98 & 163.17 & 91.49 & 2.6 & 4.0 \\
\hline 2008 & 2001.03 & 45.43 & 40.40 & 273.57 & 4.16 & 178.88 & 106.56 & 3.2 & 4.6 \\
\hline 2009 & 2122.80 & 22.40 & 125.83 & 271.87 & 5.07 & 203.79 & 112.59 & 3.2 & 7.6 \\
\hline 2010 & 2271.40 & 19.03 & 164.78 & 290.97 & 3.03 & 239.31 & 127.67 & 4.0 & 16.5 \\
\hline
\end{tabular}

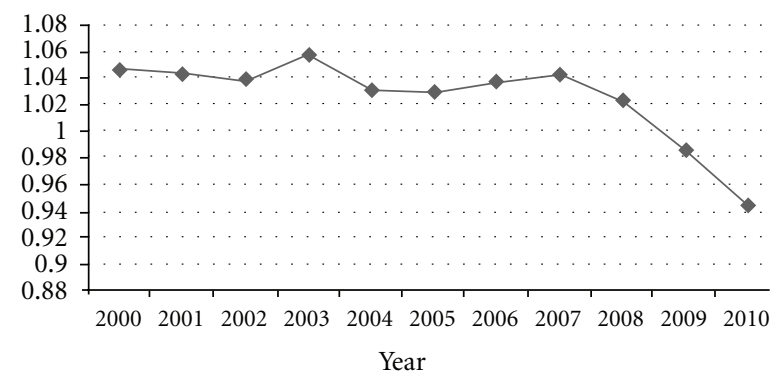

Figure 1: C/S ratio of fossil fuels in China during 2000-2010.

standard), and all the material flows are measured by the unit of "tsc," and the fossil fuels' consumption for three types of energy are collected in Tables 3(a) and 3(b).

3.1. Diversification of $\mathrm{C} / \mathrm{S}$ Ratio See Figure 1. During the years from 2000 to 2007, it was nearly stable between 1 and 1.05 implying that a certain amount of previous fossil stock should be used to solve the supply and demand difference. During this period, there was a minor peak in 2003, reflecting that the obvious expansions of real estate construction, iron, and cement based heavy industry soaring development, which lead to the remarkable tension for energy supply and consumption relation. And after 2008, this ratio is fluctuate by most time lower than 1 , which mainly attribute to the implementation of "energy saving and emission reduction" strategies in industries and domestic using. Generally speaking, from 2000 to 2010, C/S ratio of fossil fuels was decreasing roughly and the energy balance was trending into a capable supply state. Meanwhile, to better control the $\mathrm{C} / \mathrm{S}$ ratio is an effective device to control the energy balance in the original production and final consumption.

Considering three kinds of fuels, coal yield was the main growth factor, which indicated that the energy structure in China was mainly based on raw coal as the dominant sector. Moreover, coal domestic production had occupied a share ranged $73-77 \%$ compared, and for oil was around
$20 \%$ with total fossil energy during the past 11 years. The coal dominated energy structure has not dramatically reversed in that period. On average, the requirement of oil in occident countries account for 35\% [11] of the total energy, that means we have a long way to amend the energy consumption structure, especially adding new energy into consideration, such as wind power, bioenergy, and tidal energy. Oil supply in China will not be sufficient forever, an urgent support policy is needed to encourage powerful companies and organizations to blend in the international arena and exploit a high quality resource. Furthermore, the domestic natural gas yield as well as the import proportion was enlarging, which indicated a good transition in enriching energy diversity and equitability, but with a too slight step. Therefore, we still have an adequate space to optimize the energy allocation so as to change the irrational existing state of fossil fuels consumption.

3.2. Diversification of RCI. RCI is an indicator that can express the level of per capita resource possess. Table 5 indicates that RCI was 2.1 times in 2010 than that in 2000, which implied that as individuals grow more affluent, their demands move beyond basic needs. The enormous requirements for private car, energy-consumption electronic products made life quality improve deeply on the one hand, and, on the other hand, extremely aggravated fossil resources depletion. The only solution to avoid energy crisis, especially 
Table 3: (a) The fossil fuels' consumption from 2000 to 2010 in China (unit: million tsc). (b) The fossil fuels' supply ${ }^{2}$ from 2000 to 2010 within China (unit: million tsc).

(a)

\begin{tabular}{ccccc}
\hline Year & Coal & Oil & Natural gas & Total consumption \\
\hline 2000 & 1007.07 & 323.08 & 32.02 & 1362.17 \\
2001 & 1027.27 & 3278.89 & 36.10 & 1391.26 \\
2002 & 1084.13 & 355.53 & 38.26 & 1477.93 \\
2003 & 1282.87 & 389.64 & 45.95 & 1718.46 \\
2004 & 1483.52 & 454.66 & 53.36 & 1991.54 \\
2005 & 167.08 & 467.27 & 61.36 & 2199.49 \\
2006 & 1839.19 & 499.24 & 75.02 & 2413.45 \\
2007 & 1994.41 & 527.36 & 92.57 & 2614.33 \\
2008 & 2048.88 & 533.35 & 107.84 & 2690.07 \\
2009 & 2158.79 & 548.90 & 119.59 & 2827.29 \\
2010 & 2209.59 & 617.38 & 142.97 & 2969.94 \\
\hline
\end{tabular}

(b)

\begin{tabular}{ccccc}
\hline Year & Coal & Oil & Natural gas & Total \\
\hline 2000 & 950.77 & 317.94 & 32.65 & 1301.37 \\
2001 & 987.81 & 309.82 & 36.60 & 1334.22 \\
2002 & 1055.44 & 326.24 & 39.81 & 1421.48 \\
2003 & 1250.69 & 329.92 & 44.14 & 1624.75 \\
2004 & 1467.55 & 410.66 & 52.10 & 1930.30 \\
2005 & 1645.35 & 429.11 & 61.26 & 2135.72 \\
2006 & 1788.42 & 460.70 & 76.57 & 2325.68 \\
2007 & 1919.81 & 494.48 & 93.22 & 2835.45 \\
2008 & 1997.45 & 523.18 & 108.20 & 2628.83 \\
2009 & 2196.68 & 555.76 & 117.96 & 2870.41 \\
2010 & 2375.52 & 628.53 & 142.77 & 3146.82 \\
\hline
\end{tabular}

${ }^{2}$ Supply $=$ production - outport + inport .

TABLE 4: The carbon emission coefficients (CEC) for three types of fossil fuels.

\begin{tabular}{lc}
\hline Items & CEC \\
\hline Coal & 1.98 ton $\mathrm{CO}_{2} /$ ton \\
Oil & 3.07 ton $\mathrm{CO}_{2} /$ ton \\
Natural gas & 2.19 ton $\mathrm{CO}_{2} /$ ton \\
\hline
\end{tabular}

for nonrenewable energy, is to elevate utilization efficiency and attempt new renewable energy. In addition, China is the most populous developing country, whose contradiction between large energy-needed population and low per capita energy possession is always restricting the whole national development in social and economic fields. In addition, CEC from different types of the fossil fuel consumption from 2000 to 2010 in China is shown in Table 6 as a supplementary database.

3.3. Diversification of FFP. FFP, an economic value produced by the unit natural nonrenewable resource. Table 7 clearly illuminates that an obvious disparity is existing in fossil fuel productivity compared with the major energy-saving country. The level of fossil fuel productivity in China in 2010 was merely equivalent to that of The Netherlands in 1996, and Austria, Germany, and Great Britain had already owned this index nearly 1.5 times higher than that of China in 2010. The bog standard of FFP in China means not only a colossal waste of fossil fuels in production and consumption process, but also severe environmental pollution resulting in a great number of pollutants and wastes in all processes by using natural resources. The evident gap between China and other developed countries in creating economic value per unit fossil resource reflected low efficiency in energy inputoutput course. It is well accepted that economic development based on the extensive resource depletion is not the intrinsic pursuit of sustainable developing pattern, and it is needed to consummate a resource recovery system as soon as possible, promote the use of energy saving products in public, and participate in international cooperation that can develop bilateral and multilateral as well as regional collaboration in the field of new energy using and low-carbon technology [19]. Another step to solve the inefficiency in fossil fuel productivity is to change the approach of using fossil fuels into a closed material cycle mode [20] and enhance the GDP value created by per unit energy expending.

3.4. Comprehensive Analysis about Different Indexes. The variation trends of population, GDP, and RCI as well as FFP are illustrated in Figure 2. First, the population increased steadily which was fitting in with the national conditions during that time; second, GDP increased with an accelerating trend, which was not only due to the economic dynamic times in this period, but also affected by the appreciation of RMB since 2005; third, RCI was increased especially after the year 2002, meaning a society with the rapid consumption for fossil fuels; and finally, the variation of FFP was divided into two subperiods: the first half was nearly fair, however, the other half was soaring for a rapid fossil fuel economic productivity. Generally speaking, economy in China is operating well, but the extensive mode of growth could not change at once, with fossil fuel productivity impossibly boosted in a short time. However, infrastructures on fossil energy being or having been built will certainly carry weight in both economic development and the resource consumption.

3.5. $\mathrm{CO}_{2}$ Emission Analysis. From Figure 3, it was clearly demonstrated the $\mathrm{CO}_{2}$ emission distribution, and coal is the most carbon source. In China, the hidden flow ration for coal was the highest, and the energy structure could not be changed on the basis of coal consumption. That is why CEC from coal was nearly 2 times than that from oil and natural gas. From this result, using natural gas or the other low carbon emission energy is the most effective and urgent strategy for the government decision and public choice.

\section{Conclusion}

This paper analyzes the input of fossil fuels in China during 2000-2010 and proposed several indicators of MFA. 
TABLE 5: C/S ratio, RCI, and FFP of China during 2000-2010.

\begin{tabular}{|c|c|c|c|c|c|c|c|}
\hline Year & $\mathrm{C} / \mathrm{S}$ ratio & $\begin{array}{c}\text { Population } \\
\text { million }\end{array}$ & $\begin{array}{c}\text { RCI } \\
\text { (tsc/person) }\end{array}$ & $\begin{array}{c}\text { GDP } \\
\text { ( } ¥ \text { billion) }\end{array}$ & $\begin{array}{c}\text { Exchange rate } \\
(¥ / 100 \$)\end{array}$ & $\begin{array}{c}\text { GDP } \\
\text { (\$ billion) }\end{array}$ & $\begin{array}{c}\text { FFP } \\
(\$ / \text { tsc })\end{array}$ \\
\hline 2000 & 1.0467 & 1267.43 & 2.11 & 9921.4 & 827.84 & 1198.46 & 424.39 \\
\hline 2001 & 1.0427 & 1276.27 & 2.22 & 10965.5 & 827.70 & 1324.82 & 459.32 \\
\hline 2002 & 1.0397 & 1284.53 & 2.32 & 12033.2 & 827.70 & 1453.82 & 475.76 \\
\hline 2003 & 1.0577 & 1292.27 & 2.68 & 13582.2 & 827.70 & 1640.97 & 458.47 \\
\hline 2004 & 1.0317 & 1299.88 & 3.059 & 15987.8 & 827.68 & 1931.64 & 466.09 \\
\hline 2005 & 1.0299 & 1307.56 & 3.35 & 18493.7 & 819.17 & 2257.62 & 489.17 \\
\hline 2006 & 1.0377 & 1314.48 & 3.59 & 21631.4 & 797.18 & 2713.50 & 534.76 \\
\hline 2007 & 1.0426 & 1321.29 & 3.79 & 26581.0 & 760.40 & 3495.67 & 635.13 \\
\hline 2008 & 1.0233 & 1328.02 & 3.94 & 31404.5 & 694.51 & 4521.83 & 798.20 \\
\hline 2009 & 0.9850 & 1334.50 & 4.14 & 34090.2 & 683.10 & 4990.53 & 836.92 \\
\hline 2010 & 0.9438 & 1340.91 & 4.42 & 40120.2 & 696.95 & 5756.54 & 927.70 \\
\hline
\end{tabular}

TABLE 6: CEC from different types of the fossil fuel consumption from 2000 to 2010 in China.

\begin{tabular}{|c|c|c|c|c|c|c|}
\hline Year & $\begin{array}{l}\text { Coal consumption } \\
(\text { million ton })\end{array}$ & $\begin{array}{l}\text { Oil consumption } \\
\text { (million ton) }\end{array}$ & $\begin{array}{l}\text { Natural gas consumption } \\
\text { (million ton) }\end{array}$ & $\begin{array}{c}\text { CEC from coal } \\
\left(\text { million ton } \mathrm{CO}_{2} \text { ) }\right.\end{array}$ & $\begin{array}{c}\text { CEC from Oil } \\
\text { (million ton } \mathrm{CO}_{2} \text { ) }\end{array}$ & $\begin{array}{c}\text { CEC from natural gas } \\
\left(\text { million ton } \mathrm{CO}_{2}\right)\end{array}$ \\
\hline 2000 & 1409.87 & 226.15 & 18.92 & 2791.55 & 694.28 & 41.45 \\
\hline 2001 & 1438.15 & 229.51 & 21.34 & 2847.54 & 704.61 & 46.73 \\
\hline 2002 & 1517.75 & 248.87 & 22.62 & 3005.15 & 764.02 & 49.54 \\
\hline 2003 & 1795.97 & 272.74 & 27.16 & 3556.03 & 837.31 & 59.49 \\
\hline 2004 & 2076.88 & 318.26 & 31.55 & 4112.23 & 977.04 & 69.09 \\
\hline 2005 & 2339.15 & 327.09 & 36.27 & 4631.52 & 1004.15 & 79.44 \\
\hline 2006 & 2574.80 & 349.46 & 44.35 & 5098.12 & 1072.85 & 97.13 \\
\hline 2007 & 2792.12 & 369.14 & 54.72 & 5528.39 & 1133.26 & 119.85 \\
\hline 2008 & 2868.37 & 373.33 & 63.75 & 5679.38 & 1146.14 & 139.62 \\
\hline 2009 & 3022.25 & 384.22 & 70.70 & 5984.05 & 1179.55 & 154.84 \\
\hline 2010 & 3093.35 & 432.16 & 84.53 & 6124.84 & 1326.73 & 185.12 \\
\hline
\end{tabular}

In comparison with other countries, main conclusions are summed up as follows.

Generally speaking, the demand structure of coal, oil, and natural gas during the past 11 years has not changed significantly. The turning point of fossil fuel productivity appeared in 2002, and increased dramatically after 2005. Both phenomena are decided by international economic situations and domestic production levels. The former is due to good circulations of the world economy and China's entry into WTO, which lead to substantial materials input but a lack of efficiency advancements. The latter is owing to policy steering of the eleventh five-year plan unveiled in 2005, which drives the movement of technical improvement, renewable energy development, wastes recycling, and multilevel using. But we have to admit that China still has to go a long way to pursue fossil fuel productivity compared with countries like Japan and Germany.

MFA accounting system calculates environmental pressure produced by the resource depletion. Its standpoint is payments for import only cover the economic costs without environmental costs as well as hidden flows value in the process of energy production. By this token, one country can pass over the environmental cost by importing so as to reduce the domestic natural risk. From this point of view, it is necessary to shift energy strategy from export-oriented to import-oriented style and elevate the export price by considering environmental expense and enlarging import proportion, from which home resource and environment can be protected in a qualified sense. Nevertheless, it is myopia for a particular developing period in certain regions, but not beneficial for universal sustainable utility of resource. Natural wealth belongs to human beings, without boundary of different nations and territories.

\section{Discussions and Prospects}

For the existing energy supply and demand status quo, more efforts are needed to intensify energy structure reforms, though the expansion of gas domestic output and import quotation provided a new perspective. Furthermore, the unchanged conditions may be related to the existing exploitation patterns, the history of coal mining and technical problems in the development of pelagic natural gas, which are primarily reasons for the univocal energy current situation. Whereas, the future structure of energy utility will move forward to a rational and sustainable direction as long as technical progress, sufficient facilities, financing of safeguards, and national supporting policies are provided. 


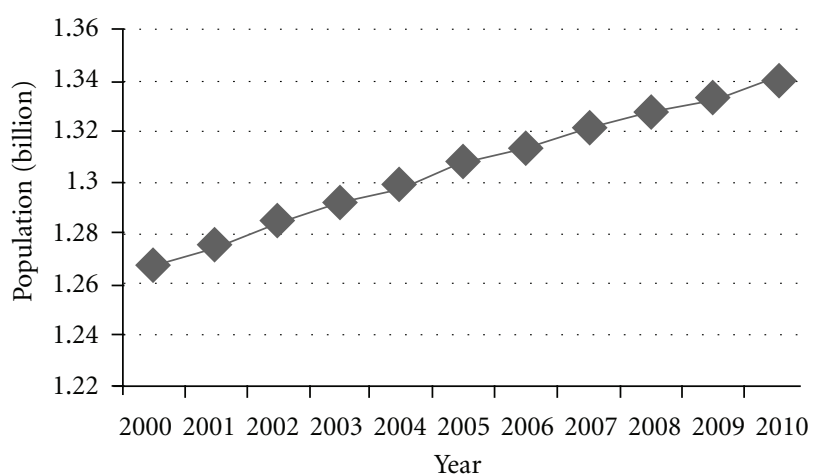

(a)

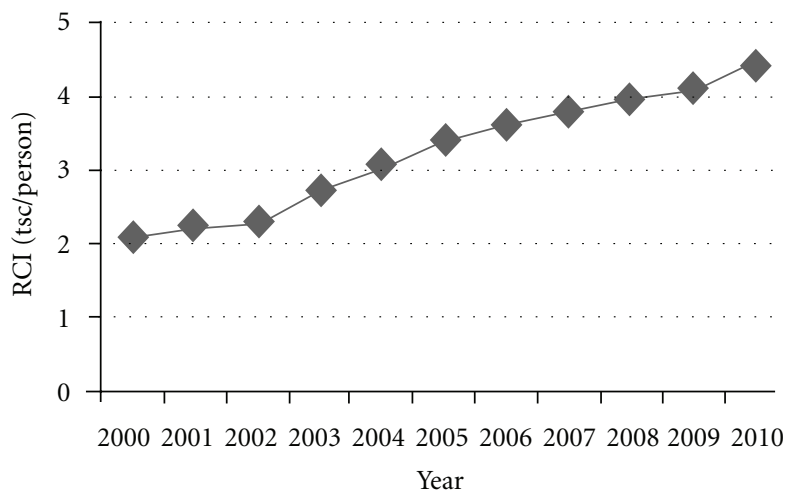

(c)

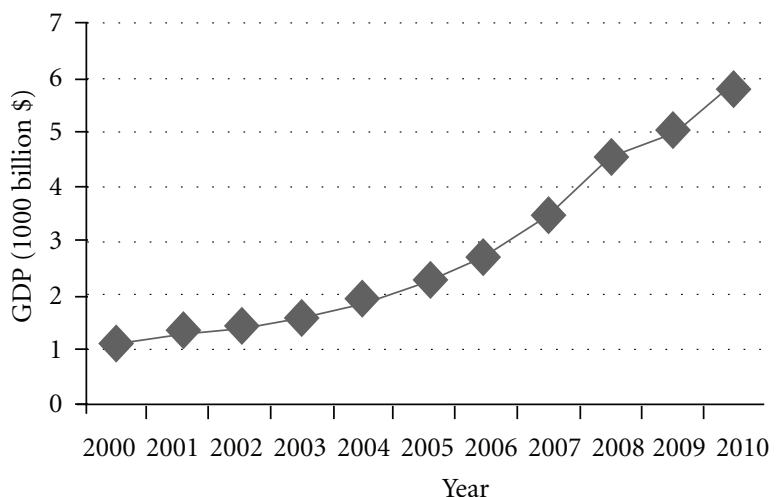

(b)

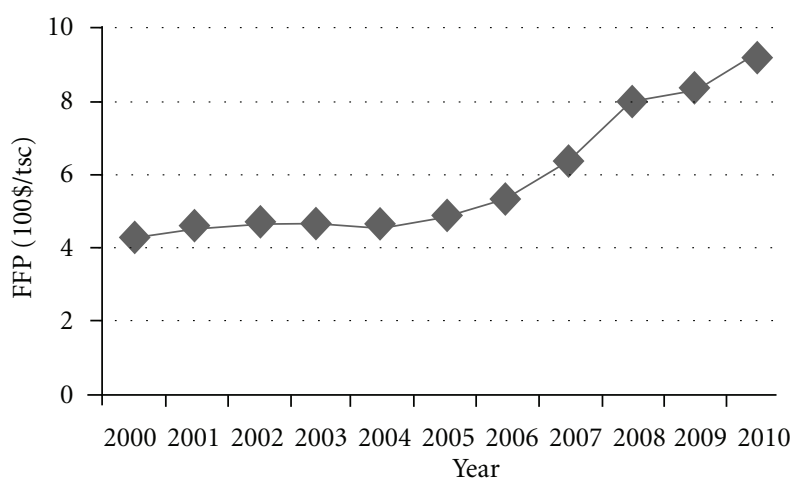

(d)

Figure 2: A comprehensive index comparison of fossil fuels in China during 2000-2010.

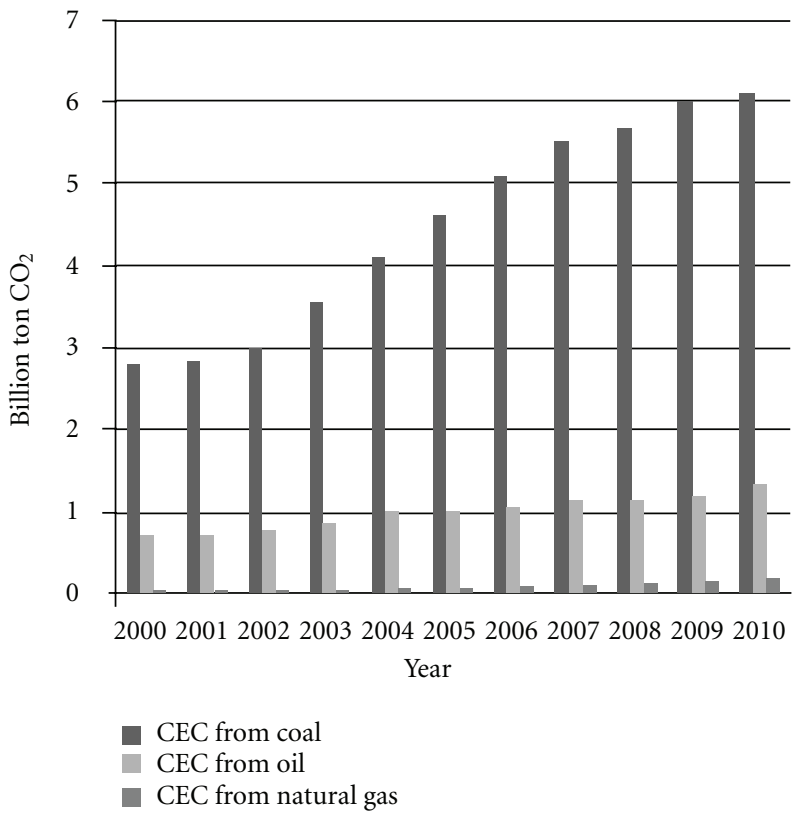

Figure 3: CEC amount from three types of fossil fuels from 2000 to 2010 in China. 
TABLE 7: Statistics of FFP in other countries during recent years (Unit: \$/tsc).

\begin{tabular}{lcccccc}
\hline Country & 1975 & 1980 & 1985 & 1990 & 1995 & 1996 \\
\hline Austria & 649.9 & 887.8 & 620.3 & 1197.9 & 1415.7 & 1362.2 \\
Germany & 649.8 & 984.6 & 751.6 & 1451.6 & 1296.6 & 1313.9 \\
Japan & 472.1 & 700.6 & 852.8 & 1410.2 & 2543.3 & 2255.7 \\
Netherlands & 460.5 & 670.9 & 437.1 & 884.2 & 1018 & 949.1 \\
Great Britain & 1487.01 & 1714.01 & 1012 & 1517.1 & 1482.2 \\
\hline
\end{tabular}

Meanwhile, the "closed material cycle mode" that with the process of "energy production $\rightarrow$ energy consumption $\rightarrow$ recycled energy $\rightarrow$ recycled energy reuse" should be extensively implemented in extensive energy based industries in order to decrease the $\mathrm{C} / \mathrm{S}$ ratio value and create more economic value by consuming the previous amount of energy consumption. And the bundled infrastructures or strategies should be followed up, for example, the generalization of garbage classification with recycled waste energy appliance, popularization of new energy vehicle service facilities.

The transformation of GDP has necessary connections with the resource consumption intensity and the fossil fuel productivity. To accomplish the target of energy saving and emission reducing, and also to keep to the path of sustainable development, it is necessary to rely on domestic research and developments as well as global introductions of advanced technology in enhancing efficiency and reduced consumption for internal upswing.

Apparently, material and energy streams are dependent with each other in a different manner, so the simplex material flow analysis is not comprehensive in identifying the energy consumption in an environmental economic system. Next, we should combine the material and energy analysis to understand the social metabolism of fossil fuels from all angles. At the same time, the indexes and their variation trends provide reasonable explanations for future policy drafts in energy saving and emission reducing by evaluating the recent 11 years' resource consumption and production efficiency.

\section{Acknowledgments}

This study was supported by the National Science Foundation for Innovative Research Group (no. 51121003), Key Program of National Natural Science Foundation (no. 50939001 and 41271543), and Program for New Century Excellent Talents in University (NCET-09-0226). The authors are especially grateful for the financial support from Beijing Development Area Co., Ltd.

\section{References}

[1] E. Matthews, C. Amann, S. Bringezu et al., Weight of Nations: Material Outflows From Industrial Economies, World Resources Institute, Washington, DC, USA, 2000.

[2] U. R. Ayres and V. A. Kneese, "Production, consumption and externalities," American Economic Review, vol. 59, no. 3, pp. 282-297, 1969.
[3] M. Fischer-Kowalski, "Society's metabolism: the intellectual history of materials flow analysis, part I, 1860-1970," Journal of Industrial Ecology, vol. 2, no. 1, pp. 61-78, 1998.

[4] A. Adiranse, S. Bringezu, A. Hammond et al., Resource Flows: the Material Basis of Industrial Economies, World Resources Institute, Washington, DC, USA, 1997.

[5] European Communities, Economy-Wide Material Flow Accounts and Derived Indicators: A methodological Guide, Official Publications of the European Communities, Luxembourg, 2001.

[6] J. P. Muñzo and K. Hubacek, "Material implication of Chile's economic growth: combining material flow accounting (MFA) and structural decomposition analysis (SDA)," Ecological Economics, vol. 65, no. 1, pp. 136-144, 2008.

[7] G. Q. Chen and B. Chen, "Resource analysis of the Chinese society 1980-2002 based on exergy-part 1: fossil fuels and energy minerals," Energy Policy, vol. 35, no. 4, pp. 2038-2050, 2007.

[8] X. Q. Chen and L. J. Qiao, "Material flow analysis of Chinese economic-environmental system," Journal of Natural Resource, vol. 15, no. 1, pp. 17-23, 2000.

[9] M. Xu and T. Zhang, "Material flow analysis of fossil fuel usage in the Chinese economy," Journal of Tsinghua University, vol. 44, no. 9, pp. 1166-1170, 2004.

[10] C. Y. Xia, "Review on studies of economy, wide material flow analysis," Journal of Natural Resources, vol. 20, no. 3, pp. 415421, 2005.

[11] B. F. Schmidt, The MIPS-Concept: Bridging Ecological, Economic, and Social Dimensions With Sustainability Indicators, United Nations University, Tokyo, Japan, 1999.

[12] Y. Chen and N. S. Deng, "Environmental management approach geared to the 21st century-matter and energy flow analysis," Chongqing Environmental Science, vol. 25, no. 3, pp. $1-5,2003$.

[13] X. Q. Chen, Natural Geography, Peking University Press, Beijing, China, 2001.

[14] W. Chen, W. Tang, and X. C. Zhang, "The resource and development study for China's Coal," Coal Economic Research, no. 7, pp. 6-11, 2003.

[15] CESY, China Energy Statistic Yearbook, China Environment Yearbook Press, Beijing, China, 2005-2011.

[16] CESY, China Statistic Yearbook, China Statistics Press, Beijing, China, 2001-2011.

[17] http://www.cngascn.com/html/news/show_news_w1_1_20258 .html.

[18] IPCC, IPCC Guidelines For National Greenhouse GasInventories, Institute for Global Environmental Strategies, Hayama, Japan, 2007. 
[19] H. P. Aubauer, "A just and efficient reduction of resource throughput to optimum," Ecological Economics, vol. 58, no. 3, pp. 637-649, 2006.

[20] N. Duan, "Material metabolism and circular economy," China Environmental Science, vol. 25, no. 3, pp. 320-323, 2005. 

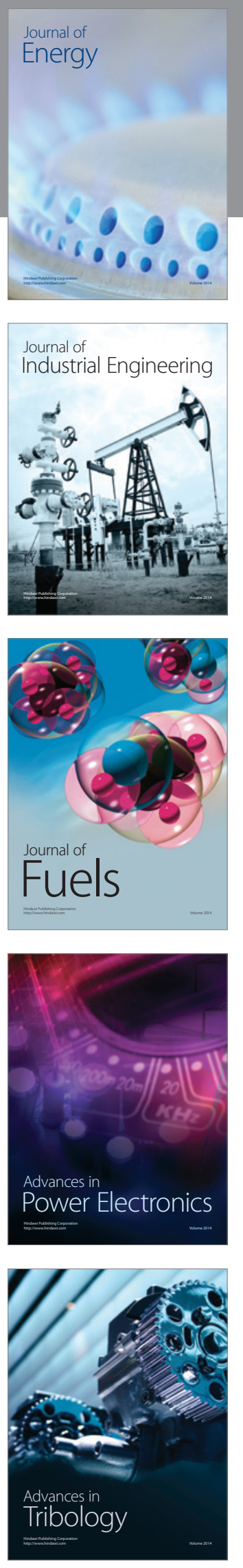
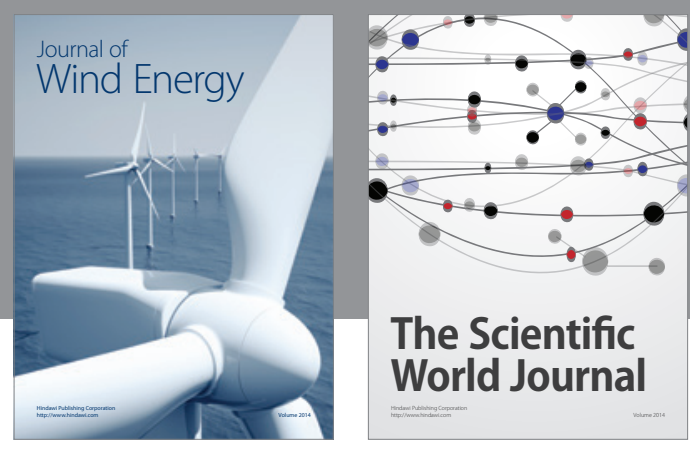

The Scientific World Journal

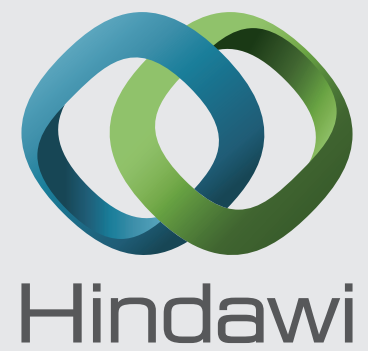

Submit your manuscripts at http://www.hindawi.com
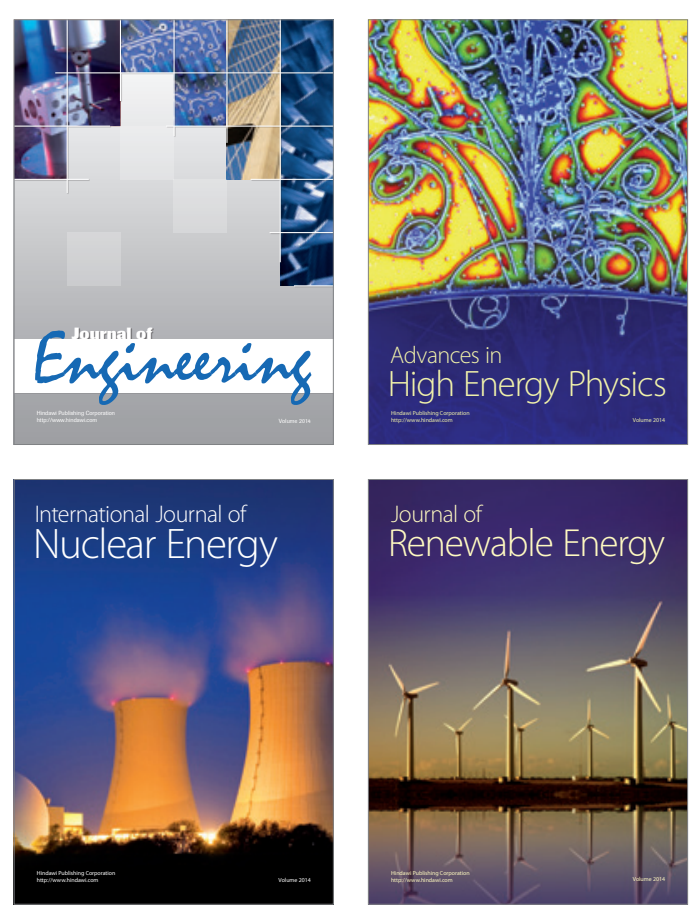

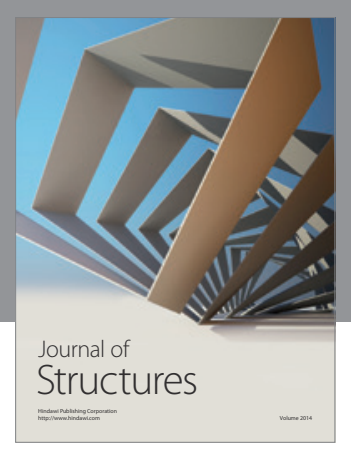

Rotating
Mechinery
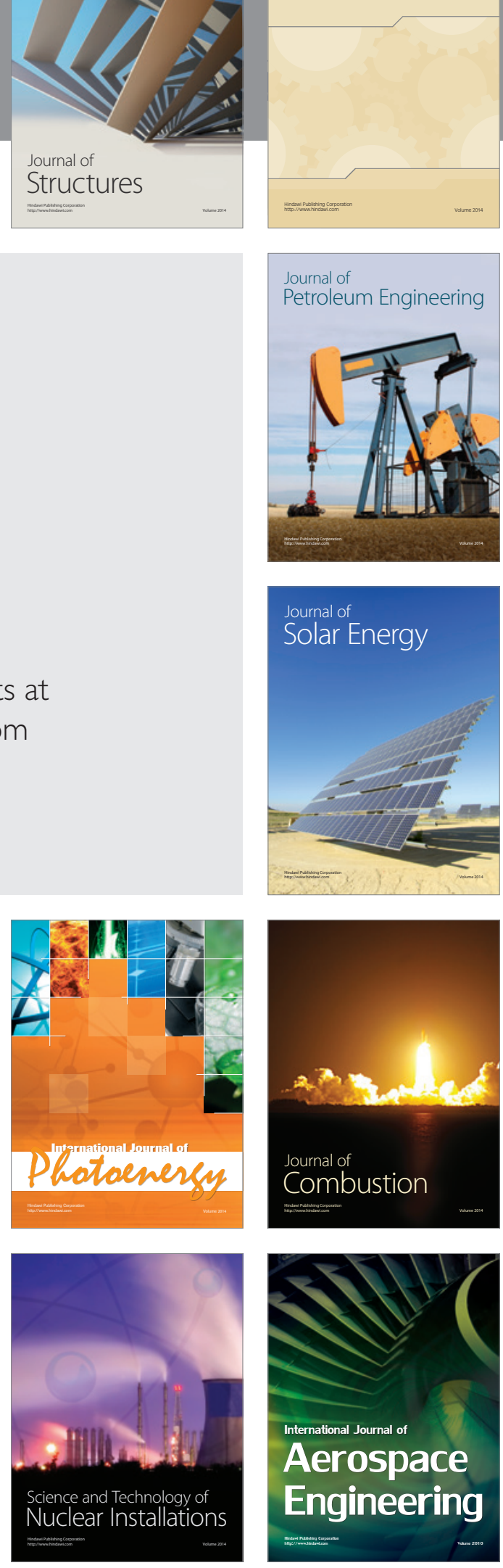